\title{
54. Data Journalism and Digital Liberalism
}

\author{
Dominic Boyer
}

\begin{abstract}
How the rise of data journalism intersects with political liberalism.

Keywords: liberalism, sedentary journalism, screenwork, lateral messaging, autological individuality, data journalism
\end{abstract}

The past 30 years have witnessed a massive transformation of the journalistic profession and the organizational culture of news-making. The causes and effects of that transformation are too complex to detail here. Suffice it to say that the model of print and terrestrial broadcasting that still seemed quite robust as late as the 199os has been almost fully replaced by a digital-first model of news media created by the rise of the Internet, search engines and social media as dominant communication and information systems, and by the widespread financialization and privatization of news media driven by the economic philosophy of "neoliberalism." As this volume argues, proliferating digital data streams and tokens are now the default condition of journalistic practice. All journalism is now, to some extent, "data journalism." In my 2013 book The Life Informatic I described this process as "the lateral revolution," suggesting that we have witnessed an ecological shift from the dominance of radial (e.g., largely monodirectional, hub-tospoke) infrastructures of news media to lateral (e.g., largely pluridirectional, point-to-point) infrastructures (Boyer, 2013). As Raymond Williams (1974) observed in his brilliant historical study of the rise of television, electronic media have exhibited both radial and lateral potentialities since the 18th century. Where these potentialities have been unlocked and institutionalized has always been guided by social and political circumstances beyond the technologies themselves. There was a prototype fax machine over a century

Bounegru, L. and J. Gray (eds.), The Data Journalism Handbook: Towards a Critical Data Practice. Amsterdam: Amsterdam University Press, 2021 DOI 10.5117/9789462989511_CH54 
before there was an obvious social need for such a technology and so its formal "invention" was delayed accordingly. Broadcasting systems ranging from radio to television first became socially necessary, Williams (1974) argues, once what he terms the "mobile privatization" of Western society had advanced to the point that it was difficult for government and industry to locate and communicate with citizen-consumers other than by "blanket" radial messaging over a whole terrain. The lesson for our contemporary situation is simply that we should not assume that the recent data revolution in news journalism is solely or even primarily driven by new technologies and infrastructures like the Internet. We should rather be attentive to how news media have evolved (and continue to evolve) within a more complex ecology of social forces.

Williams' approach informed the concept of "digital liberalism" that I developed in The Life Informatic to capture a hunch that I developed during my fieldwork with news journalists in the late 2000 s that there was a symbiotic relationship between the digital information practices of news journalists and the broader neoliberalization of society and the economy since the $1980 \mathrm{os}$. I was, for example, interested in the increasing importance of screenwork among news journalists. One might consider screenwork as an infrastructural precondition for the rise of data journalism. Screenwork first emerged as an aspect of news-making in the 197os and 1980 s, driven by organizational initiatives in news media and elsewhere in Western corporate culture to harness personal computers and office-based digital information systems to generate new production efficiencies. In the news industry, computerization was originally viewed as a means of improving word-processing speed and reducing labour costs through the automation of composition and some copyediting work. But in the process of institutionalization, computers rapidly became involved in every aspect of news production from marketing to layout to archiving, creating new opportunities for automating tasks previously accomplished directly by humans and for concentrating remaining production tasks in the hands of fewer news workers. Veteran journalists who recalled work life before computerization frequently told me how much larger the support staff had been, how much more time they now spent at their desks, and how their individual workloads had increased.

It is true that news journalism has always had its sedentary side. Typewriting, for example, also involved seated production; as did telephone use before cellular systems. The crucial difference between previous forms of sedentary journalism and its contemporary variant is how screenwork currently channels an unprecedented number of key journalistic tasks (e.g., 
word processing, text editing, archival research, breaking news monitoring, surveillance of the competition, and intra-office communication and coordination) through a single interface with a normally fixed location. The combined importance of smartphone use and fast-time social media like Twitter for news journalism has made mobile screenwork at least as important as desktop screenwork, but it has done little to change the phenomenon of journalists being "glued to their screens." Few would dispute now that the screen interface has become a central aspect of journalistic practice. Almost everything journalists do, almost every source of information, almost every professional output involves their engagement with one or more screens.

This co-location of critical tasks creates convenience but also distraction. Many journalists report feeling overwhelmed by the sheer number and speed of the data streams they have to manage. It is important to recognize that the experience of data journalism is frequently an anxious one. In my field research, journalistic screen workers frequently reported having to rely on other trusted news sources for judgements (for example, as to news value) because their own abilities were so overtaxed. It is easy to see how screenwork contributes to the much-maligned "herd mentality" of contemporary news, with distracted, overwhelmed journalists often relying on each other for real-time guidance while data streams move on at breakneck pace.

Knowing that the dominance of screenwork did not emerge in a vacuum, this is where a parallel investigation of neoliberalism proves fruitful. Classical liberalism came into being in the 17 th and 18 th centuries as European intellectual culture adapted to the realities of the formation of colonial empires across the world. The cultural dominance of medieval Christian conservatism and even Renaissance humanism were increasingly displaced by social philosophies that emphasized labour, liberty, private property and productivity. A critical problem for early liberalism was how to make the pursuit and possession of private property a virtuous path, since it would seem to threaten to deprive the poor of their share of God's gifts to humanity. The solution was to emphasize that human science and industry's ability to improve the productive use of resources combined with the sheer abundance of the new colonial frontier meant that the acquisition of private property need not be antithetical to Christian values. A perhaps unintended consequence of this new ethical formation was concentrated attention on the individual as a subject of reason, action, freedom and virtue. As liberalism developed in conjunction with the rise of capitalism and its modern ways of life, the individual became an increasingly important figure in Western culture. At first, the individual sought to harmoniously counterbalance the restrictive forces of "society," but increasingly individuality was positioned 
as an end in itself where all social and economic relations ultimately served to develop and enable robust, productive, self-sustaining individuals. These individuals were imagined as being ideally free of social determination and instead free to think and act as they wished. I describe this model of individuality, following anthropologist Elizabeth Povinelli, as "autological" in its working ideological assumption that individuals to a great extent are capable of "making themselves," a proposition that remains cherished across the liberal political spectrum today.

What does all this have to do with computer screens you might ask? It is true that the first great ventures in analogue and digital computation took place in the 1930s as the Keynesian social democracies of the mid-2oth century readied themselves for war. But the development of personal computation that was the more direct forerunner of contemporary screenwork developed during the 1970 s and 1980 s at the same time that neoliberalism rose to political and philosophical dominance as Keynesian social democracy seemed to collapse under the weight of the multiple geopolitical crises of the late 1960 s and 1970 (the Vietnam War, the Arab-Israeli conflicts, the formation of OPEC, among others). Where liberalism had long believed that the best way to pursue public interests was by empowering private interest, one might describe neoliberalism as ruthlessly autological in its empowerment of private interests at the expense of public investments and institutions. The neoliberal turn in politics and policy had a profoundly negative impact on the kind of public interest news journalism that accompanied Keynesian mid-2oth-century norms even as it propelled massive new investments in communication and information infrastructures like the Internet, satellite broadcasting and cellular telephony around the world. The imagination and creation of these infrastructures originally had very little to do with news media. The Internet, as is widely known, came into being through the shared interests of military defence and research science. Less well known, but equally important, was the usefulness of fast-time transnational communications for financial practices like arbitrage. Nevertheless, the new information and communication infrastructures impacted all areas of social communication including, of course, news-making. Their net effect was the radical strengthening of point-to-point lateral messaging capacities as well as the pluralization and retemporalization of hub-tospoke broadcasting such that even though radial messaging still exists, it is increasingly transnational and asynchronous. The model of the nation sitting down to listen to the evening news together simply does not exist in any practical sense in most parts of the world, even in Europe and Asia where stronger public broadcasting traditions have endured. 
Our contemporary news ecology does not actually guarantee robust individualism even though it has made finding community and trusted information a more precarious venture. But where the rubber hits the road for digital liberalism, so to speak, is in the individualizing experience of screenwork (and screenplay for that matter). The evolution of personal computation, the Internet and social media were deeply shaped by the social importance of neo/liberal principles of maximizing individual capacities for action, communication and ideation. Over the past decade, an increasing percentage of the population (over $70 \%$ of the United States, for example) carries with them an all-purpose portable media device operating like a fifth limb of the body. That limb allows access to multiple information flows, the possibility of curating those flows to reflect personal interests and desires, and myriad ways to message personal views and thoughts and to constitute self-centred micropublics. It is both the inheritor of centuries of liberal epistemology as well as the crucial device for enabling the reproduction and intensification of that epistemology in what we have come to call "the digital era." You have seen the images of strangers in a bar or on a train, everyone glued to their screens. The smartphone did not invent social estrangement of course. What it invents is a communicational interface that allows us to experience active, productive individuality, while minimizing social connectedness and accountability, even when we are crowded among strangers in any given place in the world. In other eras those strangers might have found greater occasion and opportunity in their co-presence to become unneighbourly with one another.

In short, I remain convinced that autological individuality is being reinforced by the proliferation and intensification of screen interfaces even as the fact those interfaces exist in the first place has much to do with technologies developed to materialize liberal worldviews and priorities over the course of the past few centuries. To paraphrase Marshall McLuhan, we assume we work our screens but we should recognize that our screens also work us. This juncture of mobile portable screen-based media and liberal perceptions of autological individuality is what I term "digital liberalism," and it will be interesting to see how that liberalism further evolves in the future. What if all the strangers on that train car were wearing VR headsets that allowed them immersive access to virtual worlds? How might such new media interfaces elicit new modes of individuality and sociality? Although data journalism is often suspected to share kinship with surveillance technologies and algorithmic authoritarianism, I would submit that the evolution of digital liberalism is actually data journalism's deeper history. 


\section{Works Cited}

Boyer, D. (2013). The life informatic: Newsmaking in the digital era. Cornell University Press.

Williams, R. (1974). Television. Wesleyan University Press.

\section{About the Author}

Dominic Boyer is an anthropologist, filmmaker and podcaster who founded the Center for Energy and Environmental Research in the Human Sciences (CENHS) at Rice University. 